CONF- $900733-3$

PNL-SA- -18562

DE91 004071

LUDEP: A LUNG DOSE EVALUATION PROGRAM

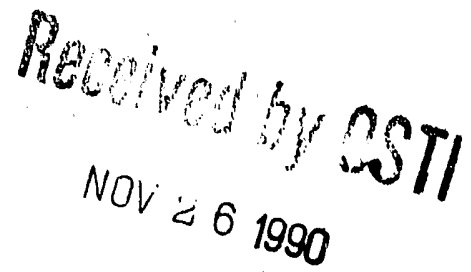

A. Birchall(a), M.R. Bailey(a)

and A.C. James

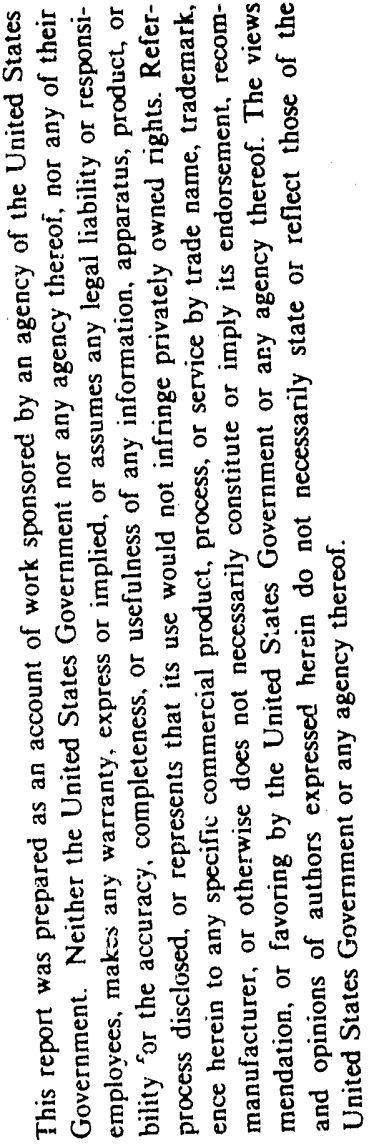

June 1990

Prepared for the

Third International Workshop on Respiratory

Tract Dosimetry Organised by Inhalation

Toxicology Research Institute

Albuquerque, New Mexico

JuTy $1-3,1990$

Work Supported by

the U.S. Department of Energy

under contract DE-ACO6-76RLO 1830

Pacitic Northwest Laboratory

Richland, Washington 99352

(a) National Radiological Protection Board, Chilton, Didcot, OXI1 ORQ United Kingdom 


\section{LUDEP: A LUNG DOSE EVALUATION PROGRAM}

by

Birchall A., Bailey M.R. and James A.C.

Abstract - A Task Group of the ICRP is currently reviewing its dosimetric model for the respiratory tract with the aim of producing a more comprehensive and realistic model which car be used both for dosimetry and bioassay purposes. This in turn requires deposition, clearance, and dosimetry to be treated in a more detailed manner than in the current model. In order to examine the practical application and radiological implications of the proposed model, a microcomputer program has been developed in a modular form so that changes can be easily included as the model develops. LUDEP (Lung Dose Evaluation Program) is a user-friendly menu-driven program which can be operated on any $\mathrm{IBM}^{\dagger}$-compatible PC. It enables the user to calculate (a) doses to each region of the respiratory tract and all other body organs, and (b) excretion rates and retention curves for bioassay purposes.

+ IBM is a registered trademark of International Business Machines Corp. 
The ICRP-30 lung model (1) is currently used both to estimate doses from intakes of radionuclides and, in conjunction with systemic retention models, to estimate intakes from bioassay measurements (2). There are two problems with this approach:

1. The ICRP-30 lung model is closely based on ore which was first published in $1966^{(3)}$, and since then there has been a wealth of data, both from experimental and occupational sources, suggesting behaviour different from that predicted by the model.

2. The model was developed for calculating average doses to the lung and other organs, and deposition fractions and clearance rates were chosen in order not to underestimate this radiation dose. It was not intended to be used to describe the kinetic behaviour of radionuclides accurately, nor to model the mechanistic processes involved in clearance. It is not therefore surprising to find anomalies when it is used for these purpose's.

In contrast, the proposed ICRP lung model has been designed to model, as accurately as possible, deposition, clearance and dosimetry in the human respiratory tract, and is necessarily more complicated than its predecessor. LUDEP (Lung Dose Evaluation Program) was therefore developed for two reasons.

1. To help the ICRP Task Group to examine the proposed model in detail ie. to (a) test predictions of retention and excretion, and (b) determine the implications for doses. The program was thus written in a modular form so 
that changes could be easily included as the model developed.

2. To test the practicalicy of implementing the lung model. Once the model parameters have been finalised, it is envisaged that the program could also be used by practising health physicists to evaluate doses to individuals.

DESCRIPTION OF THE PROGRAM

LUDEP is a user-friendly menu-driven program which can be operated on any IBM-compatible PC. It enables the user to calculate doses to all organs of the body, with particular emphasis on the respiratory tract. It also performs bioassay calculations by combining the proposed lung model with the ICRP-54(2) systemic empirical excretion finctions.

Deposition, clearance and dosimetry are treated individually, and ICRPrecommended defaults are assumed automatically. However, if desired, the user can enter or change all the parameters directly eg. particle size, lung physiology parameters, breathing patterns, clearance rates, masses of organs or tissues, weighting factors, quality factors etc.

The program has several built-in databases including: photon and particle emission energies and yields for 497 radionuclides(4); specific absorbed fractions for photons (5); the ICRP-30 metabolic models(1); the ICRP-54 retention functions.

LUDEP is writter in Turbo BASIC(6) and is compiled as a stand-alone program: no other software except the disk operating system (MS-DOS 2.0 or 
later) is necessiry. Execution time is fast: typically in the order of seconds, and the program, together with all its databasos, only requires about 330 kByte of disc storage space.

OPERATION OF THE PROGRAM

The program is menu-driven. The main menu is shown in Fig. 1 and gives the user a choice of 13 options. Once chosen, the screen displays either detailed information pertaining to that option or another menu. The options are now explained in more detail.

\section{Retrieve parameters from disc}

The user can retrieve all the details relating to a previous calculation by supplying the name of a previously created data set. The name is shown in the top left hand corner of the main menu (Figure 1).

Store parameters on disc

The user can store all the details that have so far been entered into the program for future retrieval. The user is asked to supply a name for the data set. The name is shown in the top left hand corner of the main menu.

\section{Enter intake regime}

The user can specify the route of intake (inhalation, ingestion or injection), the time-course (acute or chronic), and the amount in Bq. Combinations of such intakes can be chosen simultareous?y. 


\section{Enter time}

The program prompts for the time after intake (d) for which results are calculated. The default is 18250 d or 50 years.

\section{Enter/calculate deposition parameters}

This option calculates the fraction of the inhaled material instantaneously deposited in five regions of the respiratory tract: anterior llasal, extrathoracic, bronchi (generations 1 to 8 ), bronchioles (generations 9 to 15), and the alveolar-interstitium. The user can supply the aerosol parameters (Activity Median Aerodynamic Diameter (AMAD), Activity Median Thermodynamic Diameter (AMTD), the geometric standard deviation $\left(\sigma_{g}\right)$, density), and the lung physiology parameters (tidal volume, breathing rate, functional residual capacity, thoracic and extra-thoracic dead spaces

etc.) individually. Alternatively, default values for a standard man in various states of activity (sleep, rest, light work, or heavy work) can be selected. The five deposition fractions are continuously displayed on the screen as the user enters different parameter values. An option for entering the deposition fractions directly also exists.

\section{Enter mecharıical clearance parameters}

A diagram of the mechanical clearance model (7) and a list of all the ICRP. recommended default clearance parameters are displayed. The user can alter any of the mechanical clearance parameters individually.

\section{Enter translocation parameters}

A diagram of the translocation model (7) and a list of the five translocation parameters are displayed. The user can either: (a) enter the translocation values directly; (b) select values recommended by ICRP from a 
table of important compounds; (c) select the ICRP-recommended defau? values for fast, medium or slow translocation.

Select radionuclide

The user can choose one of 497 radionuclides (4). The half-life and decay data for the selected radionuclide are displayed on the screen and stored in memory for use in dosimetry calculations. The decay data consist of emissions of: alpha particles (energies and yields); beta particies (average energies, maximum energies, and yields); positrons (average energies, maximum energies, and yields); electrons (energies and yields); photons (energies and yields). The selected radionuclide is also shown on the main menu.

\section{Enter/select biokinetic model}

Hitting "M" Enables the user to define the metabolic model for the chosen radionuclide. For any source organ, the user can define up to five compartments, entering the fractions of activity from blood to each compartment and the corresponding retention half-times. Thus any of the non-recycling ICRP metabolic models can be entered. Once a model has been entered, it can be stored for future retrieval. Alterratively the user can automatically select ICRP-30/48 metabolic models from a built-in database.

\section{Calculate organ doses}

This option is concerned with doses to body organs, and the user can select various sub-options. The screen display, shown in Fig 2, consists of a list of 25 source and target organs and another meriu.

Hitting "S" and " $T$ " selects the source and target organ by moving a 
highlighting bar down the appropriate column.

Hitting "C" calculates the specific effective energy (SEE) from the selected source organ to the selected target organ using the radionuclide decay database. For alphas, betas, electrons, and positrons, the specific absorbed fraction (SAF) is assumed to be either unity (source=target) or zero (source $\neq$ target). except for skeleton and bone surfaces where the ICRP-30 value is assumed. The SAFs from each source organ to each target organ for monoenergetic photons have been calculated for 12 energies, ranging from 0.01 to $4 \mathrm{MeV}(5)$ These values are included in a LUDEP data file, and linear interpolation is used to calculate the SAFs for each photon energy for the chosen radionuclide. The SEEs for aiphas, betas, positrons, electrons and photons are displayed together with the net SEE.

Hitting "A" calculates the SEE from each source organ to each target organ, and sums them for every emission. The results are stored in a matrix. This calculation is necessary before doses to body organs can be calculated. To save computation time in future calculations, the SEE matrix can be stored on disc for future retrieval.

Hitting "D" starts the dose calculation. The mechanical clearance rates, translocation rates, and metabolic model parameters are used to generate a first order compartmental model of the system. Note that 40 compartments are needed for the respiratory tract and GI tract models alone: up to 60 could be needed in ali. The intakes are combined with the deposition fractions to determine the initial amounts in each compartment. A very fast algorithm for solving first order non-recycling compartmental models $(8)$ is then used to solve the system at the specified time. The 
screen displays the amount of activity and the total riumber of disintegrations in each of the 25 source organs. These are then multiplied by the SEE matrix to give the 25 dose equivalents to each target organ. Although the ling is included as a target organ, the dose equivalent calculated in this way is the average dose equivalent (i.e. treating the lung as one composite organ). LUDEP also calculates effective dose equivalents using the standard ICRP weighting factors, and using the proposed new ICRP weighting factors (9). An example of the output from calculating the CEDE from an acute intake of $1 \mathrm{~Bq}$ of a $1 \mu \mathrm{m} \mathrm{AMAD}{ }^{239} \mathrm{PuO}_{2}$ aerosol is showr in Figure 3 .

\section{Calculate respiratory tract doses}

Figure 4 shows the screen display when this option is selected. The proposed ICRP lung model treats dosimetry in the respiratory tract in much more detail than for other organs (10). The respiratory tract is divided into 7 separate target regions: anterior nasal, extrathoracic, bronchi, bronchioles, alveolar-interstitium, thoracic lymph and extra-thoracic lymph. The sensitive cells in each of these regions are irradiated from 17 different sources within the respiratory tract. The SAFs from each of the 17 source regions to the 7 target tissues have been evaluated $(10)$, and expressed as algebraic functions of energy for alpha particles, beta particles, positrons and electrons. The SAFs (5) have not been calculated for the extrathoracic region, and so the thyroid is used as a surrogate. Thus, for photons, the SAFs from source organ to lung is used to calculate doses to thoracic regions, and the SAF from source organ to thyroid is used to cilculate doses to extrathoracic regions. 
Hitting "W", "M" or "Q" cal1s up the weighting factors and masses of the 7 target regions of the lung, or the quality factors for the 5 types of radiation (alpha, beta, electron, positron, and photons). ICRP default values are automatically assumed, but the user can alter any value individually.

Hitting "L" starts the lung calculation. The radionuclide decay data is combined with the SAFs, quality factors, and masses to give the SEEs. The disintegrations in each of the 17 sources are calculated and combined with the SEEs to give the dose equivalents to each of the 7 target tissues of the respiratory tract which are displayed on the screen. LUDEP also displays the respiratory tract weighting factors, the effective dose equivalents to each region, the net effective dose equivalent to the respiratory tract, and the thoracic activity.

Hitting "D" enables the dose to the lung to be examined in more detail. LUDEP then displays the cc tribution to each of 7 target regions from each of the 17 sources separately for each of the 5 types of radiation.

Hitting "A" enables the user to examine the 17 SAF terms for source to target and for any chosen energy.

\section{Run bioassay calculations}

Bioassay calculations are performed using the methodology outlined in ICRP publication $54(2)$. Thus systemic excretion and retention are represented by semi-empirical functions. A calculation is carried out in three steps: 
1. Select the quantity to calculate e.g. whole body retention, thoracic retention, urinary excretion rate or faecal excretion rate.

2. Enter the semi-empirical systemic function. Alternatively, LUDE.P has a built in data set of all of the systemic excretion and retention functions specified in ICRP-54 which can be called up by simply selecting the appropriate radionuclide from a menu.

3. Select the time of interest.

A method for reducing the systemic function to a mathematically equivalent first order compartmental model(11) is used to link it to the lung model, and a non-recycling algorithm $(8)$ is used to calculate the quantity of interest. The results are displayed on the screen.

An alternative to step 3 is to select a time interval and a number $n$. LUDEP then calculates the appropriate quantity of interest (e.g. urinary excretion rate) at $n$ time intervals within the range (logarithmically spaced) and stores the answer in ASCll format in a user-named file.

\section{Run DOS commands with LUDE.P in memory}

This option can be selected to hide LUDEP, together with all the information so far entered, in memory, and the user is returned to DOS. After the required DOS commands have been run, the user can retrieve LUDEP from memory by typing "EXIT". 
HARDWARE REQUIRED

The software will work on any standard IBM PC, AT, XT or true compatibles (8086, 80286, 80386, 80486) with 640 kByte internal memory, and fits (together with all its databases) onto a single 5.25 inch flo, y disc or 3.5 inch diskette. The program automatically determines the graphics ability of the PC. For EGA or VGA machines, diagrams are drawn on the screen to aid the users to enter the appropriate parameters. Colour schemes are also used to clarify inputting procedures and simplify output. A colour monitor is thus preferred although not essential. The program automatically detects whether an arithmetic co-processor (8087, 80287, or 80387) is installed. This increases computation speed by around 20 times and is desirable if the program is used regularly.

DOSIMETRY OF INHALED PLUTONIUM

In order to assess the implications for Pu dosimetry, LUDEP has been used to evaluate the committed dose equivalents to body organs following inhalation of a $1 \mu \mathrm{m}$ AMAD ${ }^{239} \mathrm{Pu}$ aerosol with translocation class "M" (Moderate:50\% translocates with a 3 day half-life and 50\% with a 100 day half-life) and class "S"(Slow: $0.1 \%$ transincates with a 10 minute half life and $99.9 \%$ with a 7000 day half-life). The standard ICRP-48 metabolic model for $\mathrm{Pu}$ is assumed, and the results are compared with ICRP-30/48 doses for solubility classification ' $W$ ' and ' $Y$ '. The committed effective dose equivalents and ALIs are also compared.

Table $1(a / b / c)$ and $2(a / b / c)$ respertively show the results for $1 \mu m$ and $5 \mu m$ AMAD ${ }^{239} \mathrm{Pu}$ aerosols. 
It seems likely that ICRP will soon recommend new weighting factors for organs. However, in order to compare the t:lo lung models, ICRP-30 weighting factors for organs (other than lung) are applied to buth. In the proposed model, a weighting factor of 0.12 is used for the thoracic region of the respiratory tract, and a weighting factor of 0.025 is used for the extrathoracic region.

Note that translocation classes " $M$ " and " $S$ " correspond to moderate and-slow translocation to blood. These vilues are recommended substitutes for solubility class ' $W$ ' and ' $Y$ ' compounds and should be used when specific information is not available on the translocation rate. Specific recommended values for plutonium nitrate and oxide may well differ from these values. 
TABLE 1. (a)

$\frac{T D E \text { and } C E D E}{C}(\mu S v)$ to Respiratory Tract regions from $1 \mathrm{~Bq} 239 \mathrm{Pu}$ ( $A M A D=1 \mu m$ )

\begin{tabular}{|l|c|c|c|c|c|}
\hline \multirow{2}{*}{$\begin{array}{l}\text { Respiratory } \\
\text { Tract } \\
\text { Region }\end{array}$} & & \multicolumn{2}{|c|}{ Moderately Soluble } & \multicolumn{2}{c|}{ Insoluble } \\
\cline { 3 - 6 } & $W_{T}$ & Dose Eq. & EDE & Dose Eq. & EDE \\
\hline ET1 & .0010 & 4.8 & 0.005 & 4.9 & .005 \\
ET2 & .0240 & 4.5 & 0.11 & 60 & 1.4 \\
BB & .0960 & 97 & 9.3 & 340 & 32 \\
bD & .0180 & 41 & 0.74 & 170 & 3.1 \\
AI & .0060 & 13 & 0.079 & 360 & 2.1 \\
LN(ET) & .0001 & 0.2 & 0.00002 & 100 & 0.01 \\
LN(TH) & .0001 & 6.2 & 0.0006 & 1700 & 0.17 \\
\hline Total & 0.145 & $\left(14^{2}\right)$ & 10 & $\left(390^{2}\right)$ & 39.4 \\
\hline
\end{tabular}

1 represents mean lung dose (ic. energy in $\left(A I+\mathrm{S}^{3}+\mathrm{bb}+L \mathrm{LN}_{\mathrm{TH}}\right) / 1 \mathrm{~kg}$ ) 
TABLE 1(b) $\operatorname{CDE}(\mu S v)$ to organs from $1 \mathrm{~Bq}{ }^{239} \mathrm{Pu}(\mathrm{AMAD}=1 \mu \mathrm{m})$

\begin{tabular}{|l|c|c|c|c|}
\hline \multirow{2}{*}{ Organ } & \multicolumn{2}{|c|}{ Moderately Soluble } & \multicolumn{2}{c|}{ Insoluble } \\
\cline { 2 - 5 } & $\begin{array}{c}\text { ICRP-30 } \\
\text { Class 'W' }\end{array}$ & $\begin{array}{c}\text { New Model } \\
\text { trans 'M' }\end{array}$ & $\begin{array}{c}\text { ICRP-30 } \\
\text { Class' } Y^{\prime}\end{array}$ & $\begin{array}{c}\text { New Mode 1 } \\
\text { trans 'S' }\end{array}$ \\
\hline red bone marrow & 170 & 170 & 66 & 32 \\
bone surfaces & 2100 & 2100 & 820 & 390 \\
lungs & 17 & $\left(14^{2}\right)$ & 320 & $\left(390^{2}\right)$ \\
liver & 370 & 360 & 150 & 74 \\
gonads & 31 & 31 & 12 & 6 \\
\hline ALI $(B q)^{2}$ & 230 & 240 & 610 & 1300 \\
\hline
\end{tabular}

1 represents mean lurig dose

2 calculated assuming only a non-stochastic limit of $0.5 \mathrm{~Sv}$ applies 
TABLE 1(C) CEDE ( $\mu S v)$ to organs from $1 \mathrm{~Bq}{ }^{239} \mathrm{Pu}$ (AMAD=1 $\mu \mathrm{m}$ )

\begin{tabular}{|c|c|c|c|c|}
\hline \multirow{2}{*}{ Organ } & \multicolumn{2}{|c|}{ Moderately Soluble } & \multicolumn{2}{|c|}{ Insoluble } \\
\hline & $\begin{array}{l}\text { ICRP-30 } \\
\text { Class ' } W \text { ' }\end{array}$ & $\begin{array}{l}\text { New Model } \\
\text { trans 'M' }\end{array}$ & $\begin{array}{l}\text { ICRP }-30 \\
\text { Class }^{\prime} Y \text { ' }\end{array}$ & $\begin{array}{l}\text { New Mode } 1 \\
\text { trans'S' }\end{array}$ \\
\hline $\begin{array}{l}\text { red bone marrow } \\
\text { bone surfaces. } \\
\text { lungs } \\
\text { liver } \\
\text { gonads }\end{array}$ & $\begin{array}{l}20 \\
64 \\
2.0 \\
22 \\
7.9\end{array}$ & $\begin{array}{l}20 \\
62 \\
10 \\
22 \\
7.6\end{array}$ & $\begin{array}{c}7.9 \\
25 \\
38 \\
8.9 \\
3.0\end{array}$ & $\begin{array}{c}3.8 \\
12 \\
39 \\
4.4 \\
1.4\end{array}$ \\
\hline Total CEDE ( $\mu S v)$ & 120 & 122 & 82 & 61 \\
\hline$A L I(B q)^{2}$ & 430 & 410 & 610 & 820 \\
\hline
\end{tabular}

1 calculated assuming only a stochastic limit of $50 \mathrm{mSv}$ applies 
Conclusions relating to a 1 m AMAD Pu aerosol (Table $1 \mathrm{a} / \mathrm{b} / \mathrm{c}$ )

1. The dose equivalents and effective dose equivalents to organs of the body (other than the respiratory tract) calculated using the new lung model are about the same as ICRP-30 estimates for moderately soluble Pu, but are about half the ICRP-30 estimates for irsoluble Pu. This is because in the new model, the fraction of deposited activity reaching blood is similar for moderately soluble material, but about half for insoluble material.

2. The mean lung doses calculated with the new model and the ICRP-30 model ari similar for both soluble and insoluble Pu.

3. The dose to the bronchial region $(B B)$ calculated with the new lung model is several times higher than the mean lung dose for moderately soluble Pu, but similar for insoluble Pu. As a result of this, the contribution to the EDE from lung, using the new lung model is about 5 times the ICRP-30 value for moderately soluble Pu and about the same for insoluble Pu.

4. For insoluble $\mathrm{Pu}$, the thoracic lymph nodes receive the highest dose equivalent. However, this makes a negligible contribution to the overall CEDE because of the low weighting factor (0.0001).

5. The major contribution to CEDE from lung (using the new lung model) comes from the bronchi (BB)

6. For moderately soluble Pu, the ICRP-30 ALI is $200 \mathrm{~Bq}$ and arises from the non-stochastic limit to bone surfaces. This would remain the same if the new model is used.

7. For insoluble Pu, the ICRP-30 ALI is $600 \mathrm{~Bq}$ and arises again from the non-stochastic limit to bone surfaces. However, with the new lung model, the ALI would increase to $800 \mathrm{~Bq}$ and wouid arise from the stochastic dose limit: the main contribution coming from the lungs. 
TABLE 2 (a)

$\frac{T A B L E}{C D E}$ and CEDE ( $\left.\mu S v\right)$ to Respiratory Tract regions from $1 \mathrm{~Bq}{ }^{239} \mathrm{Pu}$ ( $A M A D=5 \mu \mathrm{A} n$ )

\begin{tabular}{|c|c|c|c|c|c|}
\hline \multirow{2}{*}{$\begin{array}{l}\text { Respiratory } \\
\text { Tract } \\
\text { Region }\end{array}$} & & \multicolumn{2}{|c|}{ Moderately Soluble } & \multicolumn{2}{c|}{ Insoluble } \\
\cline { 3 - 6 } & $W_{T}$ & Dose Eq. & EDE & Dose Eq. & EDE \\
\hline ET1 & .0010 & 12 & 0.012 & 12 & 0.012 \\
ET2 & .0240 & 8.2 & 0.20 & 91 & 2.2 \\
BB & .0960 & 86 & 8.2 & 240 & 23 \\
bb & .0180 & 25 & 0.44 & 91 & 1.6 \\
AI & .0060 & 6.2 & 0.037 & 170 & 1.0 \\
LN(ET) & .0001 & 0.35 & 0.00003 & 160 & 0.016 \\
LN(TH) & .0001 & 4.6 & 0.0655 & 1000 & 0.10 \\
\hline Total & 0.145 & $\left(6.8^{2}\right)$ & 8.9 & $\left(180^{2}\right)$ & 28 \\
\hline
\end{tabular}

1 represents mean lung dose 
IABLE 2(b) CDE ( $\mu S v$ ) to organs from $1 \mathrm{~Bq}{ }^{239} \mathrm{Pu}$ ( $A M A D=5 \mu(11)$ )

\begin{tabular}{|c|c|c|c|c|}
\hline \multirow{2}{*}{ Organ } & \multicolumn{2}{|c|}{ Moderately Soluble } & \multicolumn{2}{|c|}{ Insoluble } \\
\hline & $\begin{array}{l}\text { ICRP-30 } \\
\text { C. lass ' } W \text { ' }\end{array}$ & $\begin{array}{l}\text { New Mode } 1 \\
\text { trans }{ }^{\prime} M '\end{array}$ & $\begin{array}{l}\text { ICRP }-30 \\
\text { Class'y' }\end{array}$ & $\begin{array}{l}\text { New Model } \\
\text { trans 'S' }\end{array}$ \\
\hline $\begin{array}{l}\text { red bone marrow } \\
\text { bone surfaces } \\
\text { lungs } \\
\text { liver } \\
\text { gonads }\end{array}$ & $\begin{array}{c}190 \\
2300 \\
6.0 \\
410 \\
35\end{array}$ & $\begin{array}{c}86 \\
1100 \\
\left(6.8^{1}\right) \\
190 \\
16\end{array}$ & $\begin{array}{r}33 \\
410 \\
110 \\
75 \\
6.0\end{array}$ & $\begin{array}{c}15 \\
190 \\
\left(180^{1}\right) \\
36 \\
2.7\end{array}$ \\
\hline$A \operatorname{LL}(B q)^{2}$ & 210 & 470 & 1200 & 2600 \\
\hline
\end{tabular}

1 represents mean lung dose

2 calculated assuming only a non-stochastic limit of 0.5 Sv applies 
TABLE 2(C) CEDE ( $\mu S v$ ) to organs from $1 \mathrm{~Bq} 239 \mathrm{Pu}$ (AMAD=5 $\mu \mathrm{m})$

\begin{tabular}{|l|c|c|c|c|}
\hline \multirow{2}{*}{ Organ } & \multicolumn{2}{|c|}{ Moderately Soluble } & \multicolumn{2}{c|}{ Insoluble } \\
\cline { 2 - 5 } & $\begin{array}{c}\text { ICRP-30 } \\
\text { Class 'W' }\end{array}$ & $\begin{array}{c}\text { New Model } \\
\text { trans 'M' }\end{array}$ & $\begin{array}{c}\text { ICRP-30 } \\
\text { Class'Y' }\end{array}$ & $\begin{array}{c}\text { New Model } \\
\text { trans 'S' }\end{array}$ \\
\hline red bone marrow & 22 & 10 & 3.9 & 1.9 \\
bone surfaces & 70 & 32 & 12 & 5.8 \\
lungs & 0.72 & 8.9 & 13 & 28 \\
liver & 25 & 11 & 4.4 & 2.2 \\
gonads & 8.6 & 4.0 & 1.5 & 0.68 \\
\hline Total CEDE $(\mu S v)$ & 130 & 67 & 36 & 39 \\
\hline ALI $(B q)^{2}$ & 400 & 750 & 1440 & 1300 \\
\hline
\end{tabular}

1 calculated assumirig only a stochastic limit of $50 \mathrm{mSv}$ applies 
Conclusions from comparisons of results from $1 \mu \mathrm{m}$ and $5 \mu \mathrm{m}$ AMAD Pu aerosols 1. For moderately soluble Pu, the ICRP-30 model predicts similar ALIs for 1 $\mu \mathrm{m}$ and $5 \mu \mathrm{m}$ AMAD aerosols. However, the new model predicts an increalse from 200 to $500 \mathrm{~Bq}$ as the AMAD increases from 1 to $5 \mu \mathrm{m}$. The ALI stlll arises from the non-stochastic limit to bone surfaces.

2. For insoluble $\mathrm{Pu}$, the ICRP-30 model predicts that the ALI will arise from the dose to bone surfaces and will increase from 600 to $1200 \mathrm{~Bq}$ as AMAD increases from $1 \mu \mathrm{m}$ to $5 \mu \mathrm{m}$. The new model predicts that the ALI will arise from the stochastic limit and increase from 800 to $1300 \mathrm{~Bq}$ as the AMAD increases from $1 \mu \mathrm{m}$ to $5 \mu \mathrm{m}$.

\section{FUTURE EXTENSIONS}

It is planned that future versions of LUDEP will include the contribution from daughter progeny, a method for estimating intakes from biological monitoring results, and a method for dealing with age dependence.

\section{ACKNOWLEDGEMENTS}

The work of Drs M.R. Bailey and A. Birchall was partially supported by the CEC under Contract BI6-0347-Iten 2. The work of Dr A.C. James was supported by the U.S. Dept. of Energy under contract DE-ACO6-76RLO 1830.

REFERENCES 
1. International Commisuion on Radilogdeal Protection. Publication 30 , Limits for Intakes of Radionuclides by workers. PART 1 , Ann. ICRP $\underline{2}(3 / 4),(1979):$ PART 2: Ann,ICRP壬 $(3 / 4),(1980) ;$ PART $3: \underline{6}(2 / 3),(1981):$ and PART 4: 19(4), (1988).

2. International Commission on Radiological protection. Publication 54: Individual Monitoring for Intakes of Radionuclides by Workers: Desjgn and Interpretation, Ann, ICRP $19(1-3)$ (1988).

3. ICRP Task Group on Lung Dynamics. Deposition and Retention Models for Interial Dosimetry of the Human Respiratory Tract. Health Phys. 12,pp.173207. (1966)

4. Radiation Shielding Information Centre (RSIC), Oak Ridge National Laboratory, Oak Ridge, Tennessee 37831, USA. (1989)

5. Cristy M. and Eckerman K.F. Specific Absorbed Fractions of Energy at Various Ages from Internal riston Sources. VII Adult Male. Report No. ORNL/TM-8381/V7. Oak Ridge National Laboratory, Oak Ridge, Tennessee 37831, USA. (1987).

6. Turbo BASIC: Borland International. 4585 Scotts Valley Drive, Scotts Valley, California 95066. (1989)

7. Balley M.R., Birchall A., Cudaihy R.G., James A.C. and Roy M. Respiratory Tract Clearance Model for Dosimetry and Bioassay of Inhaled Radionuclides. Rad. Prot. dosim (in press) 
8. Birchall A. A Microcomputer Algorithm for Solving Compartmental Models Involving Radionuclide Transformations. Health Phys. 50(3) pp.389-397. $(1986)$.

9. International Commission Radiological Protection. Draft Recommendations of the International Comnission on Radiological Protection. ICRP/90/G-01 (1990)

10. James A,C., Gehr P., Masse R., Cuddihy R,G., Cross F.T., Birchall A., Durham J.S. and Briant J.K. Dosimetry Model for Bronchial and Extrathoracic Tissues of the Respiratory Tract. Rad Prot dosim. (in press)

11. Birchail A. Mathematical Solutions to problems in Radiological Protection Involving Air Sampling and Biokinetic Modelling. PhD thesis. CNAA, (1989). 


\section{FIGURE LEGENDS}

Figure 1. Screen display of the main menu in LUDEP.

Figure 2. Screen display of the 'Calculate organ doses' option.

Ftgure 3. Screen display of the organ dose calculation following $1 \mathrm{~Bq}$ acute intake of $1 \mu \mathrm{m}$ AMAD ${ }^{239} \mathrm{PuO}_{2}$ particles.

Figure 4. Screen display of the respiratory tract dose calculation following $1 \mathrm{~Bq}$ acute intake of $1 \mu \mathrm{m}$ AMAD ${ }^{239} \mathrm{PuO}_{2}$. particles. 


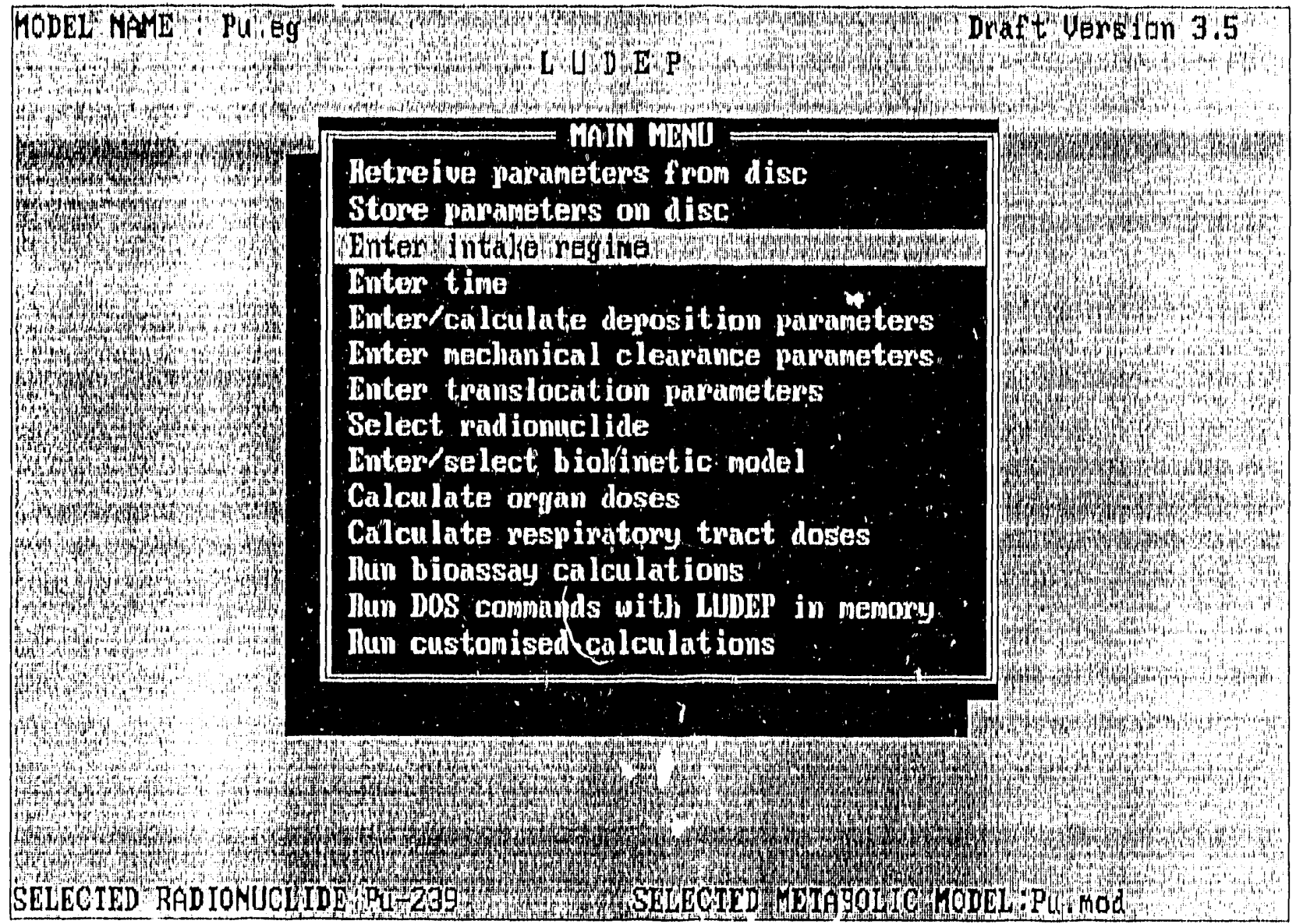




\begin{tabular}{|c|c|c|}
\hline Adrenals & 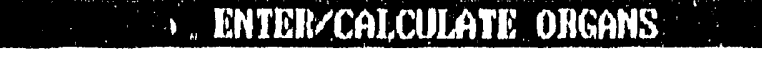 & Whins In \\
\hline 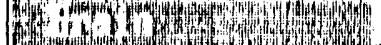 & & Brain \\
\hline (6) & SOLDRWE OWW & Bransts \\
\hline 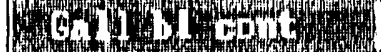 & & Gall bl wall \\
\hline 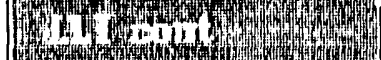 & Current radionuclide" is : Pu & LhI wa H \\
\hline 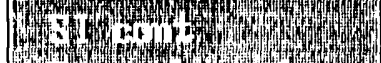 & Z phptons & S1 iall \\
\hline (1) in & Q positrans and 9 algatrons & Stonach \\
\hline moty & & ULI wall \\
\hline Whandwhy & $M F N \|$ & fitaringens \\
\hline 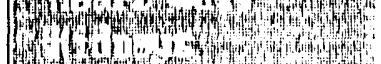 & & Liver \\
\hline W & & Lunuge \\
\hline 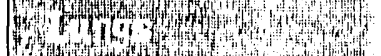 & to select Source urgan & Muscle \\
\hline M & to select Target organ & Quarias \\
\hline 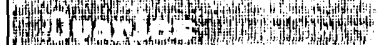 & to Calculate a single SEE & Pancineris \\
\hline 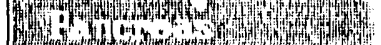 & to calculinto All SEEs & Bone marrous. \\
\hline MPfy & to Read SEE-matrix from disc & Bone suplaces. \\
\hline 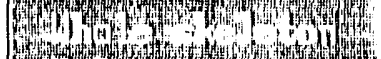 & to alter quality ractors & Skin \\
\hline moty & yo calculate Joses & Splean \\
\hline M & & Testes \\
\hline 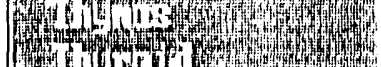 & & Thynus : \\
\hline Thom & Betabnlio modal. & Urimary bl yall \\
\hline Whind & & Utarus \\
\hline MAt & (aSG) to returin to previaus & Whole hoily \\
\hline
\end{tabular}




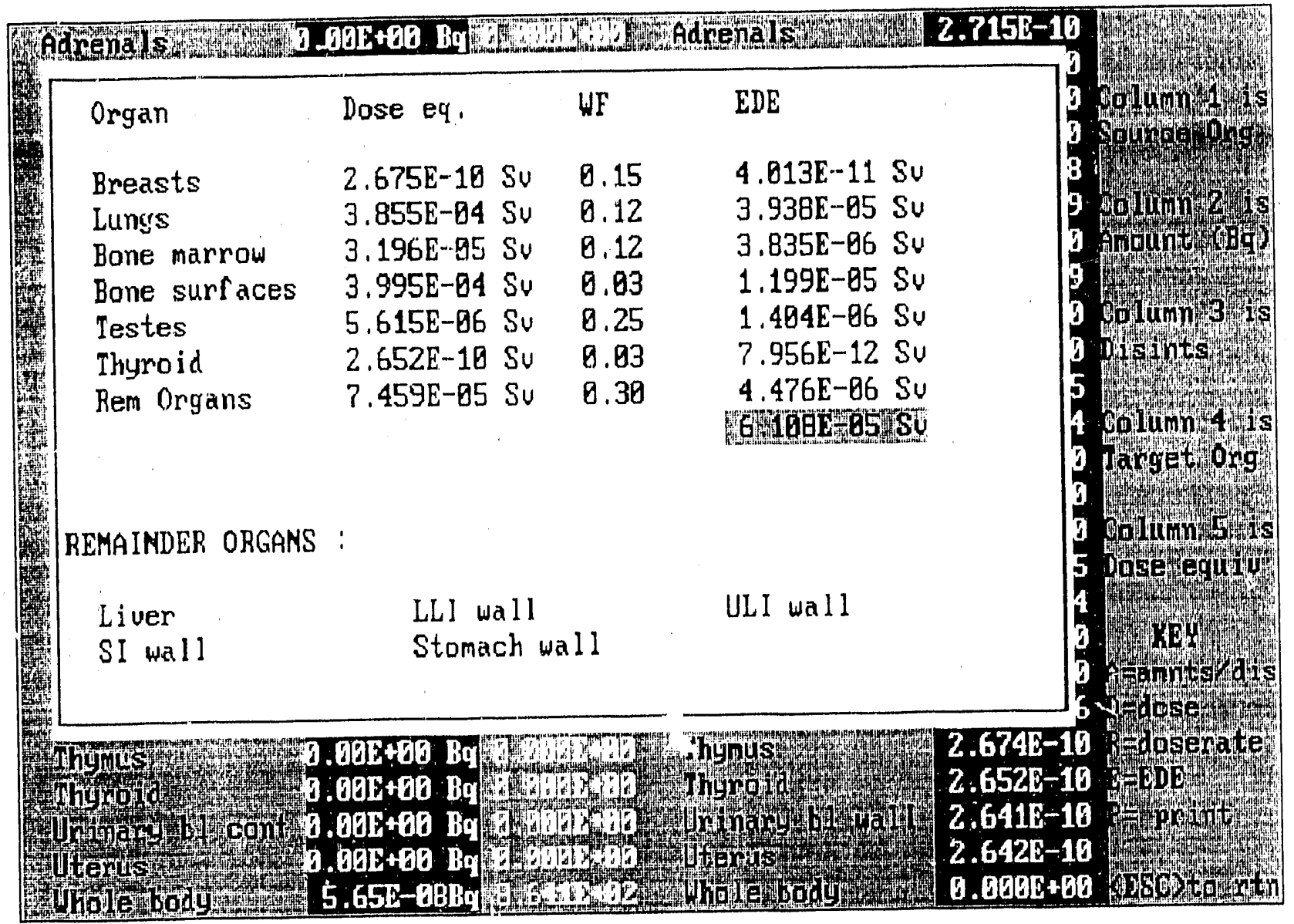




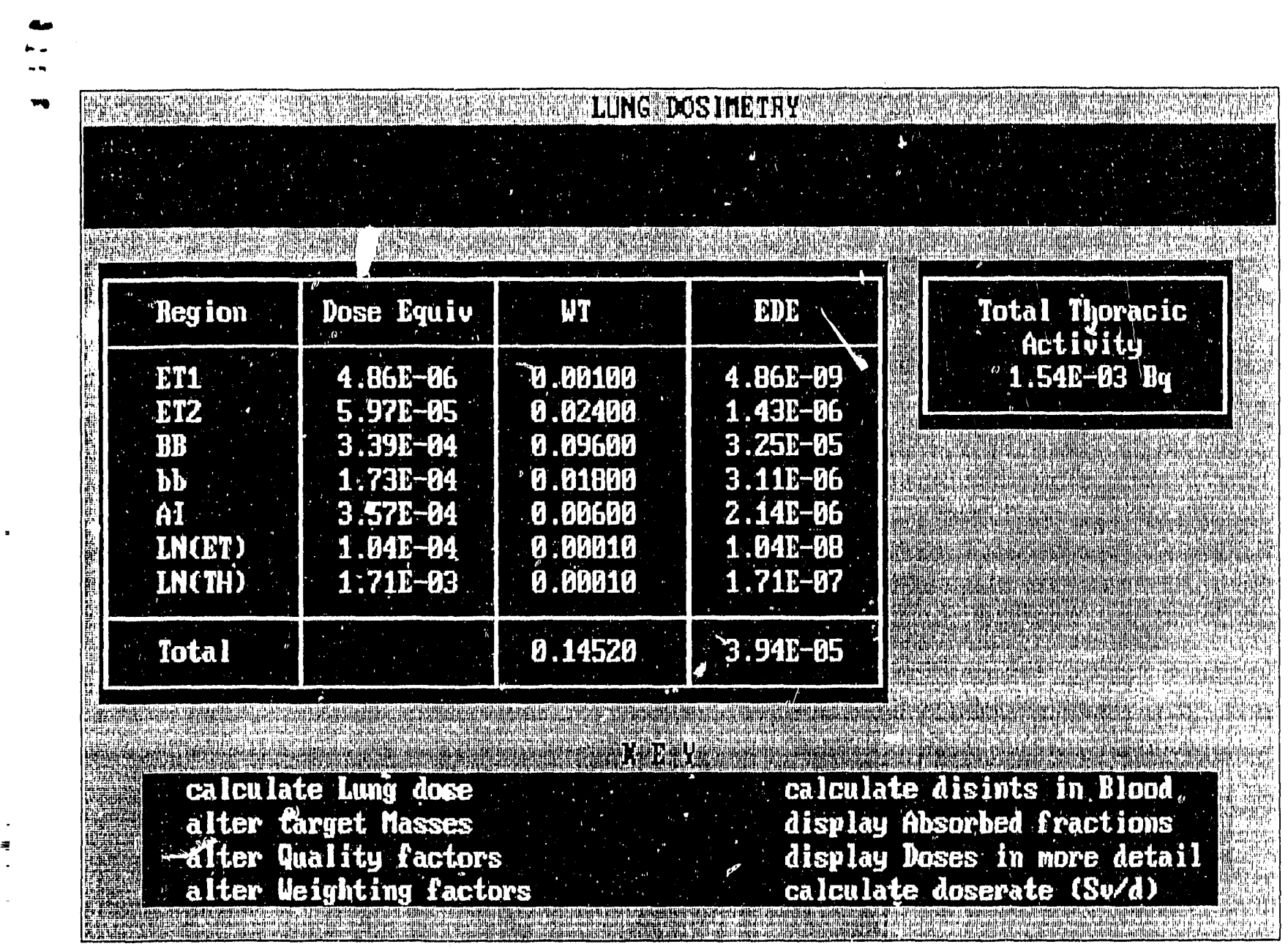



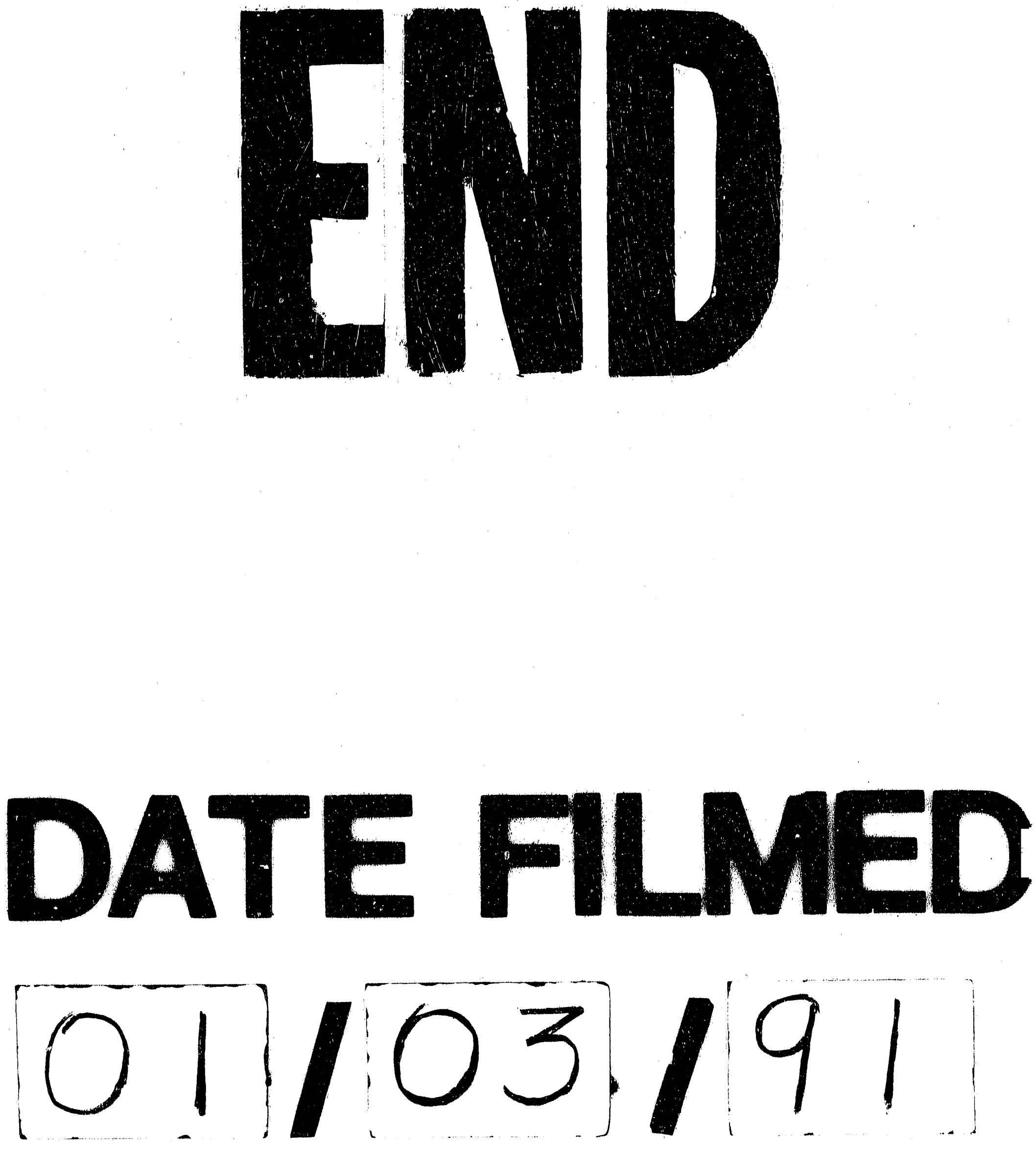
